\title{
CARACTERIZAÇÃO GEOMORFOLÓGICA EM ÁREA DE EXPANSÃO URBANA: UMA CONTRIBUIÇÃO AO PLANEJAMENTO TERRITORIAL ${ }^{1}$
}

\section{GEOMORPHICAL CHARACTERIZATION IN AREA OF URBAN SPRAWL: A CONTRIBUTION TO THE LAND USE PLANNING ${ }^{1}$}

\author{
Alan Silveira \\ Departamento de Planejamento Territorial e Geoprocessamento (Deplan/IGCE/UNESP) - Laboratório de \\ Geomorfologia (LAGEO). Avenida 24-A, 1515 - Bela Vista - Rio Claro - SP - CEP 13506-900. \\ Fone: (19) 3526-9355 ou (19) 3526-9331 - e-mail: silveira_81@yahoo.com.br
}

Cenira Maria Lupinacci da Cunha

Departamento de Planejamento Territorial e Geoprocessamento (Deplan/IGCE/UNESP) - Laboratório de Geomorfologia (LAGEO). Avenida 24-A, 1515 - Bela Vista - Rio Claro - SP - CEP 13506-900.

Fone: (19) 3526-9355 ou (19) 3526-9331 - e-mail: cenira@rc.unesp.br.

\section{Informações sobre o Artigo}

Data de Recebimento: 01/06/2011

Data de Aprovação: $21 / 10 / 2012$

\section{Palavras-chave:}

Taxonomia do relevo; caracterização geomorfológica; área de expansão urbana.

\section{Keywords:}

Taxonomy of relief; geomorphological characterization; area of urban sprawl.

\begin{abstract}
Resumo
A pesquisa pretende contribuir com o planejamento territorial em área de expansão urbana, por meio da caracterização geomorfológica embasada na proposta cartográfica dos níveis taxonômicos do relevo (ROSS, 1990, 1992 e 2001). Esta promove o estabelecimento de vários táxons ou categorias de formas de relevo, tendo como apoio a cartografia das formas do relevo de diferentes tamanhos (ROSS, 1992). A área eleita para aplicação da proposta corresponde ao setor de expansão urbana noroeste de Piracicaba (SP), estabelecido entre as latitudes $22^{\circ} 37^{\prime} 30^{\prime \prime} \mathrm{e}$ $22^{\circ} 42^{\prime \prime} 30^{\prime \prime} \mathrm{S}$, e as longitudes $47^{\circ} 41^{\prime} 15^{\prime \prime}$ e $47^{\circ} 45^{\prime} 00^{\prime \prime}$ W. Produziu-se uma Carta Geomorfológica considerando os níveis taxonômicos do relevo, principalmente aqueles de menores dimensões espaciais $\left(3^{\circ}, 4^{\circ}, 5^{\circ}\right.$ e $\left.6^{\circ}\right)$, na escala 1:10.000. Foram identificadas 14 unidades morfológicas denudacionais e unidades agradacionais ou de acumulação. Três das unidades morfológicas denudacionais necessitam de medidas mais efetivas de controle do uso da terra em função das fragilidades do relevo. As unidades Dc 5.3, já ocupada pela urbanização, a Dc 4.5 , em processo de ocupação, e a Dc 5.5, que apresenta tendência de se urbanizar, constituem-se como os setores mais fragilizados. Assim, pode-se afirmar que há necessidade de medidas mais rigorosas no processo de ocupação da área estudada, tendo em vista o número significativo de unidades morfológicas com alto grau de fragilidade do relevo, com formas erosivas associadas.
\end{abstract}

\footnotetext{
${ }^{1}$ Pesquisa financiada pela Fundação de Amparo à Pesquisa do Estado de São Paulo (FAPESP), processo no 07/51315-0.
} 


\begin{abstract}
This research aims to contribute to the land use planning in an area of urban sprawl through the geomorphological characterization based on the map proposal of the taxonomic levels of relief (ROSS, 1990, 1992 and 2001). This encourages the establishment of various taxa or categories of landforms with the support of the mapping of different sizes of relief forms (ROSS, 1992). The chosen area for implementing the proposal corresponds to the northwest sector of urban sprawl of Piracicaba (SP), located between latitudes $22^{\circ} 37^{\prime} 30^{\prime \prime}$ and $22^{\circ} 42^{\prime} 30^{\prime \prime} \mathrm{S}$, and longitudes $47^{\circ} 41^{\prime} 15^{\prime \prime}$ and $47^{\circ} 45^{\prime} 00^{\prime \prime} \mathrm{W}$. Considering the taxonomic levels of relief, especially those ones that present smaller spatial dimensions $\left(3^{\circ}, 4^{\circ}, 5^{\circ}\right.$ and $\left.6^{\circ}\right)$, in scale 1:10,000, a Geomorphological Map was made. Fourteen morphological units have been identified, some of them resulting from denudational processes and others from aggradational processes. Three of the units with denudational forms require more effective measures of land use control due to the weaknesses of the relief. The weakest sectors are Dc 5.3, which is already occupied by urbanization, Dc 4.5 that is in process of occupation and Dc 5.5, which has tendency to urbanize. Considering the significant number of morphological units with high degree of fragility and erosive relief forms, it's possible to say that there is need for more stringent measures in the process of occupation of the studied area.
\end{abstract}

\section{Introdução}

A ciência que estuda as formas de relevo tem como um de seus recursos técnicos para sua aplicabilidade, a representação cartográfica de seu objeto de estudo. Em seu universo de pesquisa, a Geomorfologia tem na cartografia geomorfológica, metodologias de caráter aplicado que objetivam contribuir para desenvolvimento da sociedade, sobretudo com a contribuição ao planejamento territorial e ambiental.

Griffits e Abraham (2008) afirmam que os mapas geomorfológicos têm especial importância para os estudos de planejamento ambiental, pois permitem compreender a distribuição espacial dos processos atuais e pretéritos que são responsáveis pelas formas de relevo das paisagens contemporâneas. Assim, a representação cartográfica do relevo pode fornecer dados sobre as condições locais para ocupação ou, ainda, em caso de ocupação já efetiva, pode auxiliar na identificação de áreas potencialmente problemáticas no futuro.

Bocco, Mendoza e Velázquez (2001) destacam a importância da cartografia geomorfológica para países em desenvolvimento ao apresentar proposta de mapeamento do relevo para a região centro-oeste mexicana. Os autores afirmam que mapeamentos em escala de reconhecimento são importantes para orientar a avaliação e planejamento de grandes territórios.

Já Nygaard e Kolstrup (2008), estudando áreas periglaciais, destacam a importância do mapeamento geomorfológico para a escolha de locais para a amostragem das formações superficiais e para o monitoramento dos processos erosivos-deposicionais em ambientes dominados por aquelas condições climáticas, as quais propiciam fluxos significativos de sedimentos em certos períodos do ano.

No processo de desenvolvimento da Geomorfologia brasileira, em especial da cartografia geomorfológica, Ross (1990, 1992 e 2001), valendo-se de sua experiência de trabalho no Projeto RadamBrasil, organizou uma metodologia de mapeamento geomorfológico baseado em níveis taxonômi- cos. Sua fundamentação teórico-metodológica está atrelada principalmente às concepções de Penck (1953), quanto às forças exógenas e endógenas geradoras das formas de relevo e Guerasimov (1946) e Mescerjakov (1968), quanto aos conceitos de morfoestrutura e morfoescultura (ROSS, 1990, 1992 e 2001).

Nestes termos, a cartografia geomorfológica proposta por Ross objetiva subsidiar o planejamento ambiental em espaços físico-territoriais de diferentes dimensões (ROSS, 1992). A proposta deste trabalho assenta-se justamente na aplicação desta proposta de mapeamento geomorfológico em áreas de dimensões territoriais reduzidas, porém com grande nível de detalhamento em termos de escala. A área selecionada para aplicação da proposta mencionada corresponde a um setor de expansão urbana, mais especificamente o setor noroeste do sítio urbano de Piracicaba (SP).

O diagnóstico do Plano Diretor de Piracicaba (PIRACICABA, 1991) aponta que, a partir da década de 1960, a cidade passou a se expandir de forma fragmentada, com a implementação de loteamentos públicos e privados distantes da área central. Assim, eixos de expansão da malha urbana foram detectados, sendo que o Plano Diretor de 1991 já acusava o setor noroeste como um dos vetores de expansão, ocorrendo o mesmo em seu diagnóstico de revisão em 2003 (PIRACICABA, 1991 e PÓLIS, 2003).

O setor de expansão urbana noroeste de Piracicaba, estabelecido entre as latitudes $22^{\circ} 37^{\prime} 30^{\prime \prime}$ e $22^{\circ} 42^{\prime \prime} 30^{\prime \prime} \mathrm{S}$, e as longitudes $47^{\circ} 41^{\prime} 15^{\prime \prime}$ e $47^{\circ} 45^{\prime} 00^{\prime \prime} \mathrm{W}$, é delimitado pela confluência dos rios Piracicaba e Corumbataí, a partir de suas margens direitas, abrangendo as bacias dos córregos das Ondas e Itapocu, ambos afluentes do rio Piracicaba, dois setores de interflúvios, com vertentes convexas drenadas por pequenos afluentes do rio Piracicaba, bem como a bacia do córrego da Reta e de algumas drenagens que se constituem como afluentes da margem direita do rio Corumbataí. Nestes setores, estão instalados os bairros Santa Terezinha, Vila Sônia, Parque Piracicaba (Balbo) e Vale do Sol (figura 1). 


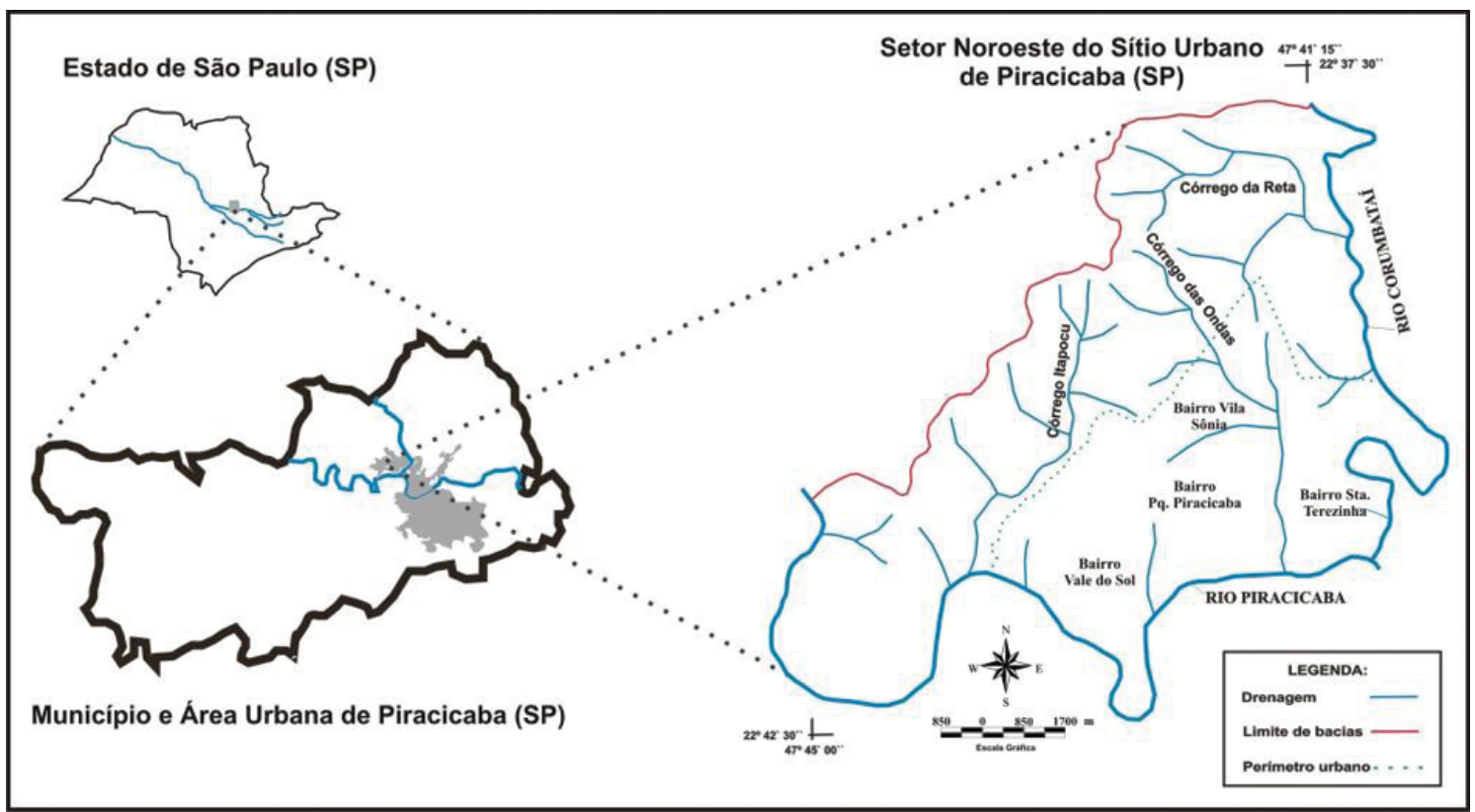

Figura 1 - Área de Aplicação da Proposta de Mapeamento.

Organização: Silveira, A.

Tem-se, portanto, como principal objetivo contribuir com o planejamento territorial de áreas de expansão urbana, por meio da caracterização geomorfológica considerando os níveis taxonômicos do relevo, sobretudo aqueles táxons de menores dimensões espaciais, haja vista a área e a escala eleita de trabalho, 1:10.000. Trata-se da aplicação de uma proposta metodológica na elaboração e interpretação de uma Carta Geomorfológica visando obter resultados que possam auxiliar o planejamento em área de expansão urbana.

\section{A proposta taxonômica do relevo e sua aplicação em área de expansão urbana.}

Ross (2001) argumenta que os trabalhos desenvolvidos por Penck (1924 e 1953), Gerasimov (1947) e Mescerjakov (1968), Demek (1967), Tricart (1965), Abreu (1982), Ab `Sáber (1969) e o projeto RadamBrasil (1982), o auxiliaram como pressupostos teóricos para a sistematização de uma proposição metodológica para o mapeamento geomorfológico em diferentes escalas. De acordo com o pesquisador (1992, p. 23):

A proposta taxonômica tem a preocupação de resolver um antigo problema não solucionado pelas propostas de classificação dos fatos geomorfológicos de Cailleux-Tricart (1965) e o esquema geral de classificação de relevo da terra de Mecerjakov (1968), que não conseguiram definir concretamente a relação de suas propostas com a cartografação das formas do relevo realmente identificadas ao se executar a cartografação geomorfológica.

[...] O que ambas classificações têm de positivo é que procuram mostrar que existe diferentes ordens de grandeza das formas do relevo e que estas grandezas têm relação com as idades das formas e com os tipos de processos atuantes(ROSS, 1992, p.23).
Assim, a proposta de mapeamento fundamenta-se na fisionomia das formas em diferentes dimensões. Tem como base interpretativa a gênese e a idade das formas, considerando que as áreas de grandes dimensões (tamanhos) são mais antigas, ao passo que, as áreas de menores dimensões registram menor idade. Propõe desta forma, o estabelecimento de seis níveis taxonômicos, tendo como apoio a cartografia das formas do relevo de diferentes tamanhos.

$\mathrm{O} 1^{\circ}$ táxon corresponde às unidades morfoestruturais ou macroestruturas. Contido neste primeiro nível taxonômico, o $2^{\circ}$ táxon proposto é representado pelas unidades morfoesculturais. Ambos os táxons, em diferentes tamanhos e dimensões escalares podem ser identificados a partir de imagens de radar com controle pelo trabalho de campo e por cartas geológicas de qualidade. Tratam-se de unidades de grandes extensões territoriais a serem cartografadas em escalas pequenas.

Contido nas unidades morfoesculturais ( $2^{\circ}$ táxon), o $3^{\circ}$ táxon sugerido é denominado por unidades morfológicas ou dos padrões de formas semelhantes. Apresentam diferenças entre si em função da rugosidade topográfica ou índice de dissecação do relevo, bem como do formato dos topos, vertentes e vales de cada padrão de formas. Assim, para o autor, é neste táxon que se estabelecem os dados morfométricos, podendo considerar a densidade da drenagem, as declividades médias e a matriz dos índices de dissecação, que compreende informações da dimensão interfluvial média, nas colunas horizontais e entalhamento médio dos vales nas colunas verticais.

Argumenta que estes padrões de formas semelhantes vão ser de duas linhagens genéticas: as formas agradacionais (acumulação), representadas pela letra símbolo "A"; e as formas de denudação (erosão), representadas pela letra símbolo “D”. Estas recebem outras letras que indicam a morfologia do topo da 
forma individualizada (reflexo do processo morfogenético), ao passo que as formas de acumulação recebem outras duas letras minúsculas, representando a gênese e o processo de geração da forma. Nestes termos, o $3^{\circ}$ táxon é representado por conjuntos de letras-símbolo maiúsculas e minúsculas, acompanhados de um conjunto de algarismos arábicos, oriundos da matriz dos índices de dissecação, sendo que para as formas agradacionais tais índices não são anexados.

Contidas de forma individualizada nas unidades morfológicas ( $3^{\circ}$ táxon), o $4^{\circ}$ táxon eleito, nomeado por formas de relevo, é indicado de maneira conjunta com o $3^{\circ}$ táxon. Dessa forma, uma unidade morfológica é constituída por formas de relevo do $4^{\circ}$ táxon, que guardam semelhanças na morfologia e morfometria.

O $5^{\circ}$ táxon representa as vertentes ou os setores de vertentes que pertencem a cada uma das formas individualizadas do relevo. Somente pode ser representado cartograficamente em trabalhos que se utilizam de fotografias aéreas em escalas de detalhe (1:25.000, 1:10.000 e 1:5.000). Para estes casos, o autor propõe que as vertentes sejam identificadas por seus setores, podendo ser dos tipos: convexa (Vc); escarpada (Ve); côncava (Vcc); retilíneas (Vr); em patamares planos (Vpp); em patamares inclinados (Vpi); assim como para os topos, como: topos convexos (Tc), topos planos (Tp), entre outras.

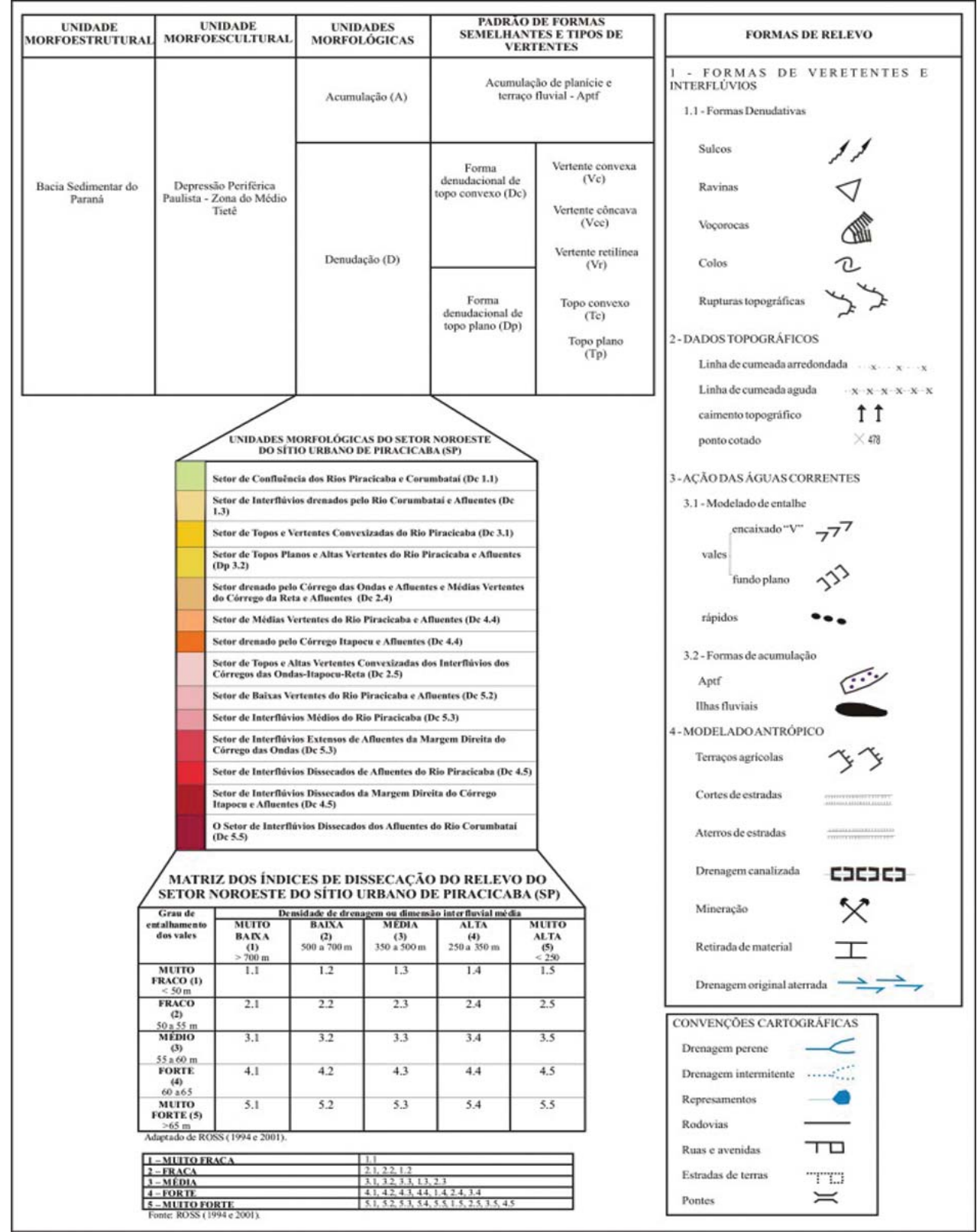

Figura 2 - Legenda da Carta Geomorfológica do Setor Noroeste do Sítio Urbano de Piracicaba (SP).

Organização: Silveira, A. 
O $6^{\circ}$ e último táxon, também representado em escalas grandes, corresponde às formas menores, produzidas pelos processos erosivos ou deposicionais atuais, que se desenvolvem por interferência antrópica ao longo das vertentes. Exemplifica o pesquisador, com base nos ravinamentos, voçorocamentos, deslizamentos, corridas de lama, bancos de assoreamento, entre outros.

Seguindo a proposta dos níveis taxonômicos do relevo proposta por Ross (1990, 1992 e 2001), a Carta Geomorfológica do setor noroeste do sítio urbano de Piracicaba foi elaborada considerando as concepções estabelecidas pelo autor a partir do $3^{\circ}$ táxon, com a utilização da Base Cartográfica (SILVEIRA, 2009), organizada com base nas cartas topográficas do Plano Cartográfico do Estado de São Paulo (SÃO PAULO, 1979 a, b, c e d) e da Carta de Declividade ou Clinográfica (SILVEIRA, 2009), como também das fotografias aéreas cedidas pelo Instituto de Pesquisa e Planejamento de Piracicaba (IPPLAP), na escala aproximada de 1:25.000, cenário de 2005 (BASE, 2005).

Dessa forma, o $1^{\circ}$ e o $2^{\circ}$ táxons da área de pesquisa correspondem, respectivamente, a Unidade Morfoestrutural da Bacia Sedimentar do Paraná e a Unidade Morfoescultural da Depressão Periférica Paulista - Zona do Médio Tietê, embasado nos trabalhos cartográficos e bibliográficos do IPT (1981b) e de Ross e Moroz (1997).

$\mathrm{O}^{\circ}{ }^{\circ} 4^{\circ}$ táxons foram mapeados diretamente na Base Cartográfica impressa. Identificaram-se as unidades morfológicas ou os padrões de formas semelhantes mediante análise da rugosidade topográfica, com auxílio da Carta de Declividade ou Clinográfica, reconhecendo unidades denudacionais de topo convexo (Dc) e de topo plano (Dp). As unidades de agradação foram identificadas pela fotointerpretação de pares estereoscópicos de fotografias aéreas, sendo mapeadas conjuntamente às áreas de acumulação de planícies e de terraços fluviais (Aptf), já que foi impossível diferenciá-las em razão da escala das fotografias.

Foram delimitadas 14 unidades morfológicas denudacionais, as quais, além de receberem sua identificação pelas letras-símbolo oriundas da matriz dos índices de dissecação, também receberam identificação nominal para facilitar a leitura do documento cartográfico na análise dos resultados da pesquisa. Assim, a figura 2 já apresenta a legenda do mapeamento elaborado contendo as unidades morfológicas mencionadas.

Posteriormente a compartimentação das unidades morfológicas, calculou-se sobre a Base Cartográfica os índices morfométricos, com informações da dimensão interfluvial média e do entalhamento dos vales, configurando a matriz dos índices de dissecação do relevo, representada na figura 2. A determinação para cada unidade morfológica de seu índice de dissecação do relevo (dimensão interfluvial média e grau médio de entalhamento dos vales) possibilitou a classificação da fragilidade do relevo (de "muito fraca", "fraca", "média", "forte" e "muito forte"), com base na tabela anexada a matriz dos índices de dissecação (figura 2).

O $5^{\circ}$ e o $6^{\circ}$ táxons foram mapeados com base na fotointerpretação de pares estereoscópicos de fotografias aéreas na escala 1:25.000. No $5^{\circ}$ táxon foram mapeadas as formas de vertentes e dos topos, sendo estas: côncavas $(\mathrm{Vc})$, convexas $(\mathrm{Vcc})$, retilíneas (Vr), topos convexos (Tc) e topos planos (Tp). Como $6^{\circ}$ táxon, foram identificadas as seguintes formas de relevo: sulcos erosivos, ravinamentos, voçorocamentos, colos, linha de cumeada arredondada, linha de cumeada aguda, caimento topográfico, vales em "V", vales em fundo chato, rápidos, rupturas topográficas, ilhas fluviais, terraços agrícolas, cortes de estradas, aterros de estradas, drenagem canalizada, cava de mineração, retirada de material, drenagem original aterrada, drenagem pluvial, entre outros. Tais informações foram mapeadas com uso das simbologias, bem como sua organização na legenda, valendo-se da proposta de Tricart (1965), como apresentado na figura 2.

O quadro 1 sintetiza as fases investigativas (táxons) e a sequência dos procedimentos técnicos cartográficos levantados na proposta de Ross, bem como os procedimentos cartográficos adotados para o mapeamento geomorfológico da área de estudo.

\section{Quadro 1 - Síntese dos Procedimentos de Mapeamento.}

\begin{tabular}{|c|c|c|c|}
\hline Táxons & Investigação & \begin{tabular}{|c|} 
Procedimentos \\
Cartográficos de Ross \\
(proposta taxonômica \\
do relevo 1990, 1992 e \\
2001 ) \\
\end{tabular} & $\begin{array}{l}\text { Procedimentos Cartográficos Adotados } \\
\text { na Pesquisa com base na proposta de } \\
\text { Ross }\end{array}$ \\
\hline $1^{\circ} \mathrm{e} 2^{\circ}$ & $\begin{array}{l}\text { Identificação da } \\
\text { Unidade } \\
\text { Morfoestrutural e } \\
\text { Unidade } \\
\text { Morfoescultural que } \\
\text { se insere a área de } \\
\text { estudo } \\
\end{array}$ & $\begin{array}{l}\text { Uso de imagens de } \\
\text { radar, cartas geológicas } \\
\text { e execução de trabalho } \\
\text { de campo. }\end{array}$ & $\begin{array}{l}\text { Cansulka de } \quad \text { Mapeamentos } \\
\text { Geomorfológicos do Estado de São Paulo: } \\
\text { IPT (1981) e Ross e Moroz (1997). }\end{array}$ \\
\hline $3^{\circ} \times 4^{\circ}$ & $\begin{array}{l}\text { Mapeamento das } \\
\text { Unidades } \\
\text { Morfológicas ou } \\
\text { Padrões de Formas } \\
\text { Semelhantes e } \\
\text { Formas de Relevo }\end{array}$ & 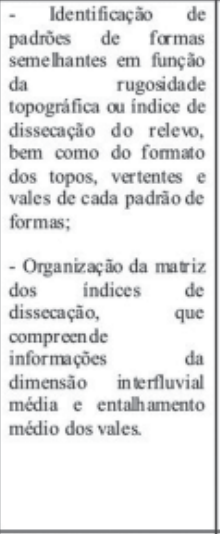 & 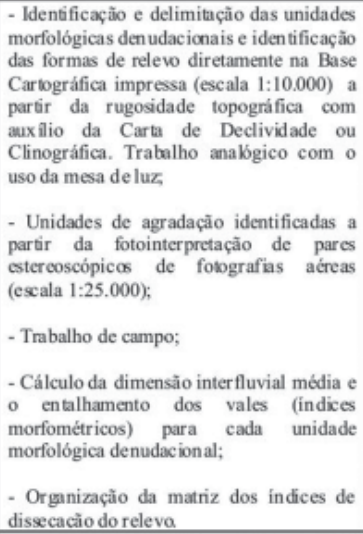 \\
\hline $5^{\circ} \times 6^{\circ}$ & $\begin{array}{c}\text { Mapeamento das } \\
\text { Formas de Vertentes e } \\
\text { Formas de Processos } \\
\text { Atuais }\end{array}$ & $\begin{array}{l}\text { Representados } \\
\text { cartograficamente } \mathrm{cm} \\
\text { trabalhos que se } \\
\text { utilizam de fotografias } \\
\text { aćreas cm escalas de } \\
\text { detalhe como } 1: 25.000 \text {, } \\
1: 10.000 \mathrm{e} 1: 5.000 \text {. }\end{array}$ & $\begin{array}{l}\text { Fotointerpretação de pares } \\
\text { estereoscópicos de fotografias aéreas na } \\
\text { escala 1:25.000; } \\
\text { - Trabalho de Campo. }\end{array}$ \\
\hline
\end{tabular}

Organização: Silveira, A. 


\section{Caracterização Geomorfológica em Área de Expan- são Urbana: estudo de caso do Setor Noroeste do Sítio Urbano de Piracicaba (SP).}

O setor noroeste do sítio urbano de Piracicaba está estabelecido na Unidade Morfoescultural da Depressão Periférica Paulista - na Zona do Médio Tietê, embutido na Unidade Morfoestrutural da Bacia Sedimentar do Paraná, mais especificamente na borda leste da Bacia Sedimentar mencionada. Esculpida predominantemente em sedimentos do Paleozóico, corresponde a uma área deprimida embutida entre as escarpas avançadas da zona das cuestas e o planalto cristalino atlântico, com topografia pouco acidentada em uma faixa de cerca de 450 quilômetros de comprimento, de norte a sul, e de aproximadamente 100 quilômetros de largura média (PENTEADO, 1976).

No mapa geomorfológico do Estado de São Paulo, elaborado por Ross e Moroz (1997), o setor noroeste piracicabano ficou caracterizado pela presença de colinas de topos amplos e convexizados, sendo classificados na categoria de alta fragilidade. Compreendem os autores como alta fragilidade potencial, as formas muito dissecadas, com vales entalhados associados a vales pouco entalhados, com alta densidade de drenagem; áreas sujeitas a processos erosivos agressivos, com probabilidade de ocorrência de movimentos de massa e erosão linear com voçorocas (ROSS e MOROZ, 1997).

Tais informações puderam ser verificadas em escala de maior detalhe por meio da Carta Geomorfológica do Setor Noroeste do Sítio Urbano de Piracicaba (figura 3). Foram identificadas 14 grandes unidades morfológicas denudacionais (Dc e Dp) e unidades agradacionais ou de acumulação (Aptf), que correspondem ao $3^{\circ}$ táxon. Para facilitar a leitura dos resultados obtidos com o documento cartográfico elaborado, tais informações foram organizadas com base nessas unidades, seguindo a lógica sequencial da fragilidade do relevo, embasado na matriz dos índices de dissecação, de "muito baixa" a "muito forte", a qual se encontra na figura 2. Tais dados estão sintetizados no quadro 2 . As informações encontradas na Carta de Declividade ou Clinográfica (SILVEIRA, 2009) foram somadas as informações da dimensão interfluvial média e do entalhamento dos vales, enriquecendo a caracterização morfométrica.

Entre estas 14 unidades denudacionais identificadas na área estudada, algumas podem ser destacadas quanto suas características geomorfológicas e interferências antrópicas vinculadas à urbanização. Destacam-se três setores: o primeiro já está ocupado pela urbanização (Dc 5.3); o segundo apresenta-se em processo de ocupação (Dc 4.5); e o terceiro, apresenta tendência de se urbanizar (Dc 5.5).

O Setor de Interflúvios Extensos de Afluentes da Margem Direita do Córrego das Ondas (Dc 5.3) está ocupado pelo bairro Vila Sônia, conforme pode ser visto na figura 3A. Corresponde à unidade denudacional de topo convexo com grau de entalhamento dos vales "muito forte" $(\geq 65 \mathrm{~m})$ e dimensão interfluvial "média" (350 a $500 \mathrm{~m}$ ), o que a caracteriza com fragilidade do relevo "muito forte". Apresenta declividades nas baixas e médias vertentes da bacia do córrego das Ondas categorizadas como fragilidade "muito fraca", "fraca" e "média" (3 a 6\%, 6 a 12\% e 12 a $20 \%$ ) e nas altas vertentes classes de declive categorizadas como "forte" e "muito forte" (20 a 30\%, 30 a 45\% e $\geq 45 \%$ ).
Quadro 2 - Síntese dos Resultados Encontrados na Carta Geomorfológica.

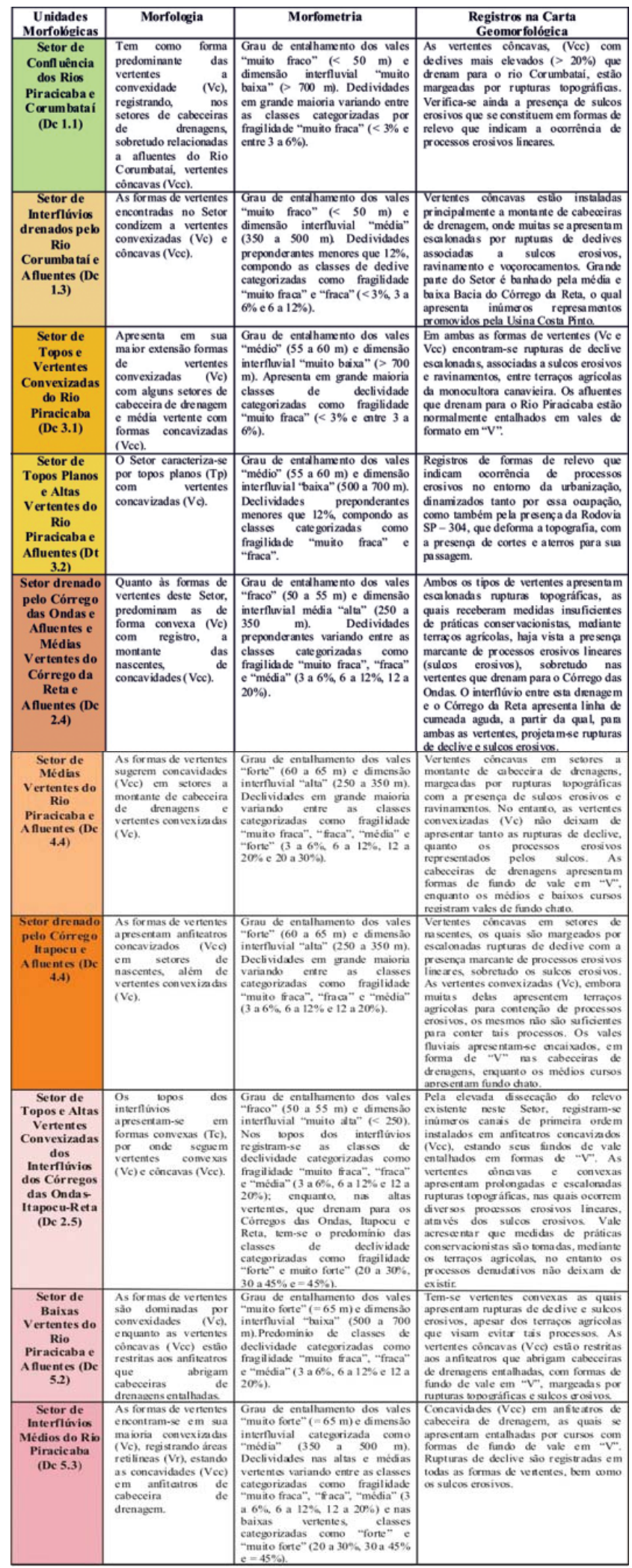




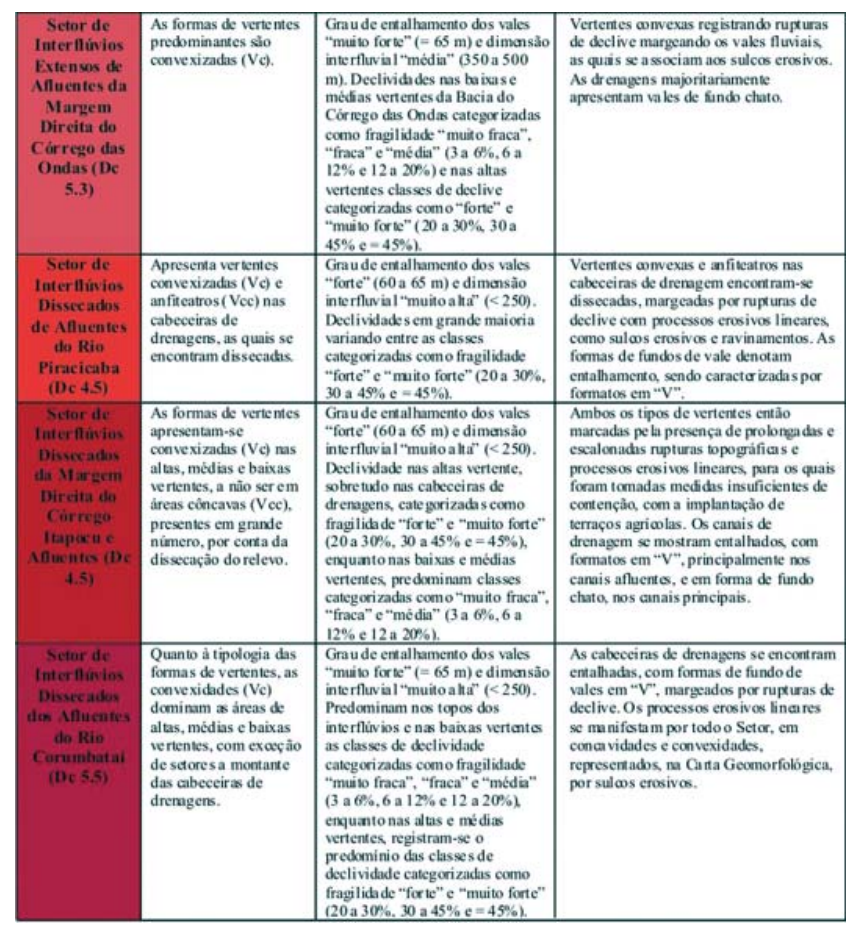

Organização: Silveira, A.
As formas de vertentes predominantemente convexizadas (Vc), hoje ocupadas pela urbanização, registram rupturas de declive margeando os vales fluviais, majoritariamente caracterizados por fundo plano. Destaca-se na figura $3 \mathrm{~A}$ as vertentes com solos desnudos das áreas de bordas urbanas, as quais apresentam rupturas topográficas associadas a sulcos erosivos. Estes registros evidenciam o típico processo de expansão da urbanização, onde as áreas periféricas a serem ocupadas, comumente são providas de formas erosivas, que propiciam por meio dos sedimentos erodidos o assoreamento dos cursos fluviais.

$\mathrm{Na}$ área urbanizada, registra-se uma drenagem, a qual seu leito original, na baixa bacia, foi aterrado, sendo desviado por canalização de sub-superfície, ou seja, abaixo da urbanização, como ilustra a figura $3 \mathrm{~A}$ e a foto 1 . Assim, a presença de processos erosivos e rupturas topográficas indicam que o processo de ocupação urbana não vem considerando as características morfométricas mencionadas que vieram a caracterizar este Setor com fragilidade do relevo "muito forte". O processo de urbanização, portanto, vem alterando os fluxos de energia e matéria do quadro geomorfológico, interferindo na topografia original, bem como na dinâmica funcional do escoamento e infiltração das águas fluviais e pluviais.

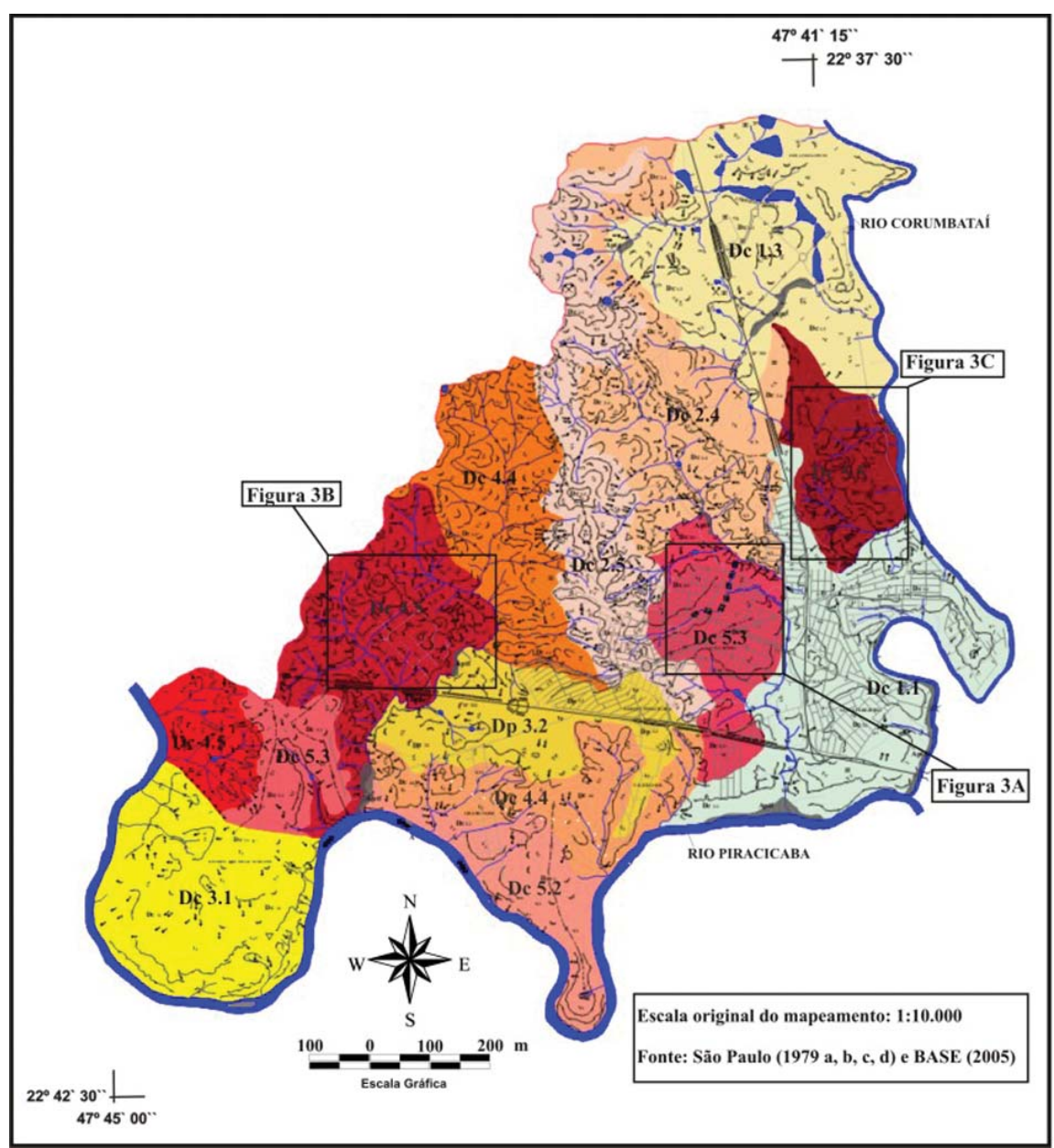

Figura 3 - Carta Geomorfológica do Setor Noroeste do Sitio Urbano de Piracicaba (SP).

A legenda encontra-se na figura 2. Organização: Silveira, A. 


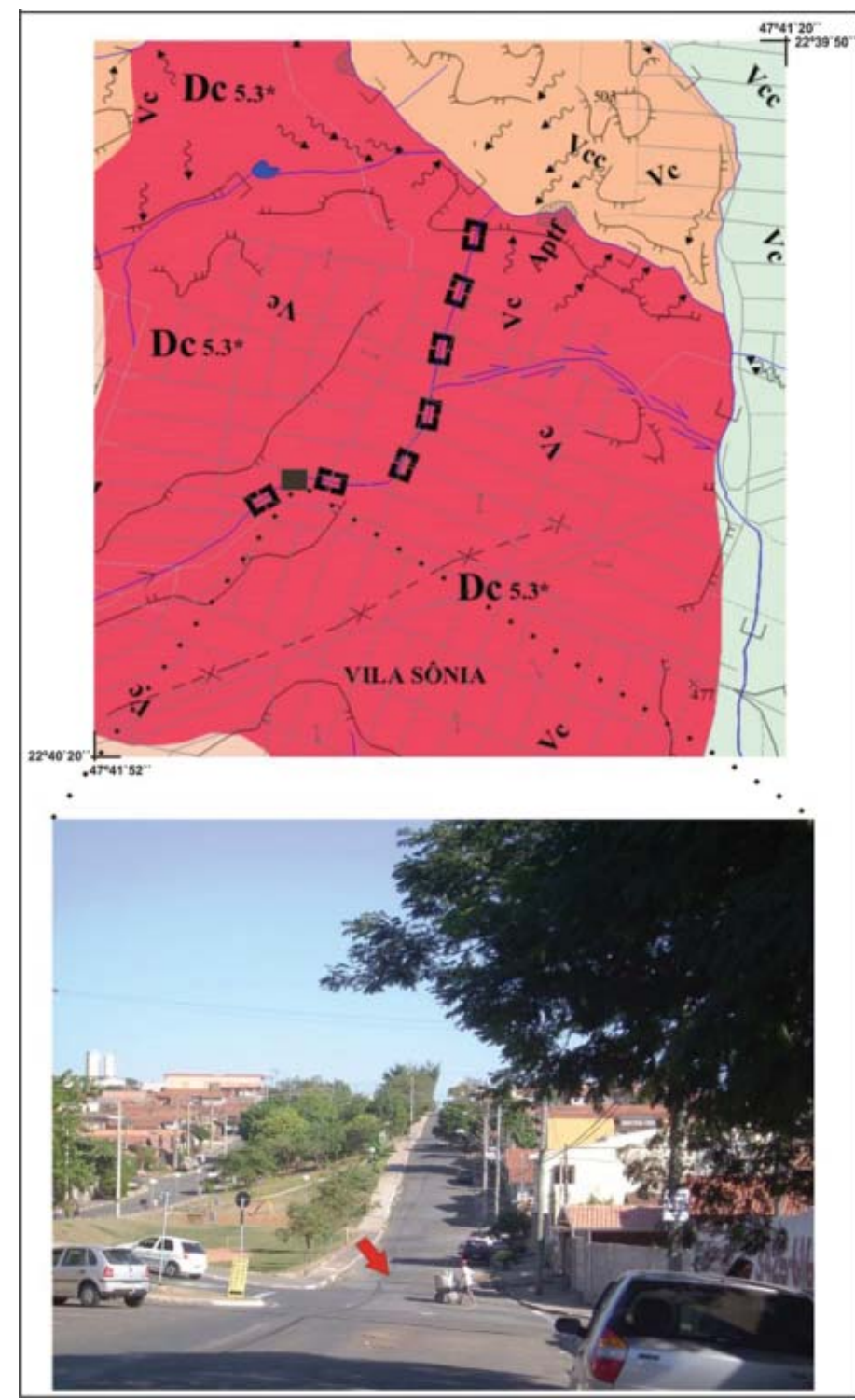

Figura $3 A$ - Setor Dc 5.3 da Carta Geomorfológica do Setor Noroeste do Sítio Urbano de Piracicaba (SP). Área urbana do bairro Vila Sonia. Ao centro, abaixo do pavimento, a drenagem canalizada representada na figura acima.

Organização: Silveira, A. (2009)

O Setor de Interflúvios Dissecados da Margem Direita do Córrego Itapocu e Afluentes (Dc 4.5) é marcado pelo processo de ocupação do bairro Bela Vista. Refere-se unidade denudacional de topo convexo com grau de entalhamento dos vales "forte" (60 a 65 m) e dimensão interfluvial "muito alta" $(<250)$, o que a caracteriza com fragilidade do relevo "muito forte". Apresenta classes de declividade nas altas vertentes, sobretudo nas cabeceiras de drenagens, categorizadas como fragilidade "forte" e "muito forte" (20 a 30\%, 30 a 45\% e $\geq$
$45 \%$ ), enquanto nas baixas e médias vertentes, predominam classes categorizadas como "muito fraca", "fraca" e "média" (3 a $6 \%, 6$ a $12 \%$ e 12 a $20 \%$ ).

As formas de vertentes apresentam-se convexizadas (Vc) nas altas, médias e baixas vertentes, a não ser em áreas côncavas (Vcc), presentes em grande número, por conta da dissecação do relevo e que, portanto, convergem para nascentes de canais perenes. Tais canais de drenagem se mostram entalhados, com formatos em "V", especialmente nos canais afluentes, e em forma de fundo plano, nos canais principais.

As vertentes estão marcadas pela presença de prolongadas e escalonadas rupturas topográficas e formas erosivas lineares, para as quais foram tomadas medidas insuficientes de contenção, com a implantação de terraços agrícolas, conforme pode ser visto na figura 3B. Assim, as interferências antrópicas são marcadas pela presença da monocultura canavieira que vem dando lugar a chácaras e casas residenciais e de veraneio do bairro Bela Vista. Este processo de consolidação da urbanização pode ser evidenciado pela proximidade do Setor com os limites dos bairros Vila Sônia e Parque Piracicaba, bem como, pela interferência da rodovia SP-304, um dos eixos condutores do processo de urbanização do setor noroeste do sítio urbano de Piracicaba. A foto 2 exemplifica o processo de ocupação com a construção residencial em área com declividade acentuada, altamente dissecada.

O Setor de Interflúvios Dissecados dos Afluentes do Rio Corumbataí (Dc 5.5) tem significativa proximidade do bairro Santa Terezinha. Refere-se à unidade denudacional de topo convexo, com grau de entalhamento dos vales "muito forte" ( $\geq 65 \mathrm{~m})$ e dimensão interfluvial "muito alta" $(<250)$, caracterizando-a com fragilidade do relevo "muito forte". Predominam nos topos dos interflúvios e nas baixas vertentes às classes de declividade, categorizadas como fragilidade "muito fraca", "fraca" e "média" (3 a 6\%, 6 a 12\% e 12 a $20 \%$ ), enquanto nas altas e médias vertentes registram-se o predomínio das classes de declividade categorizadas como fragilidade "forte" e "muito forte" (20 a 30\%, 30 a 45\% e $\geq 45 \%$ ).

Quanto à tipologia das formas de vertentes, as convexidades $(\mathrm{Vc})$ dominam as áreas de altas, médias e baixas vertentes. A montante das cabeceiras de drenagens, registramse as morfologias côncavas (Vcc), as quais se encontram entalhadas com formas de fundo de vales em "V", margeados por rupturas de declive, o que denota elevada dissecação do relevo. Tais vertentes registram ainda formas erosivas lineares, representadas na Carta Geomorfológica (figura 3C) por sulcos erosivos. 


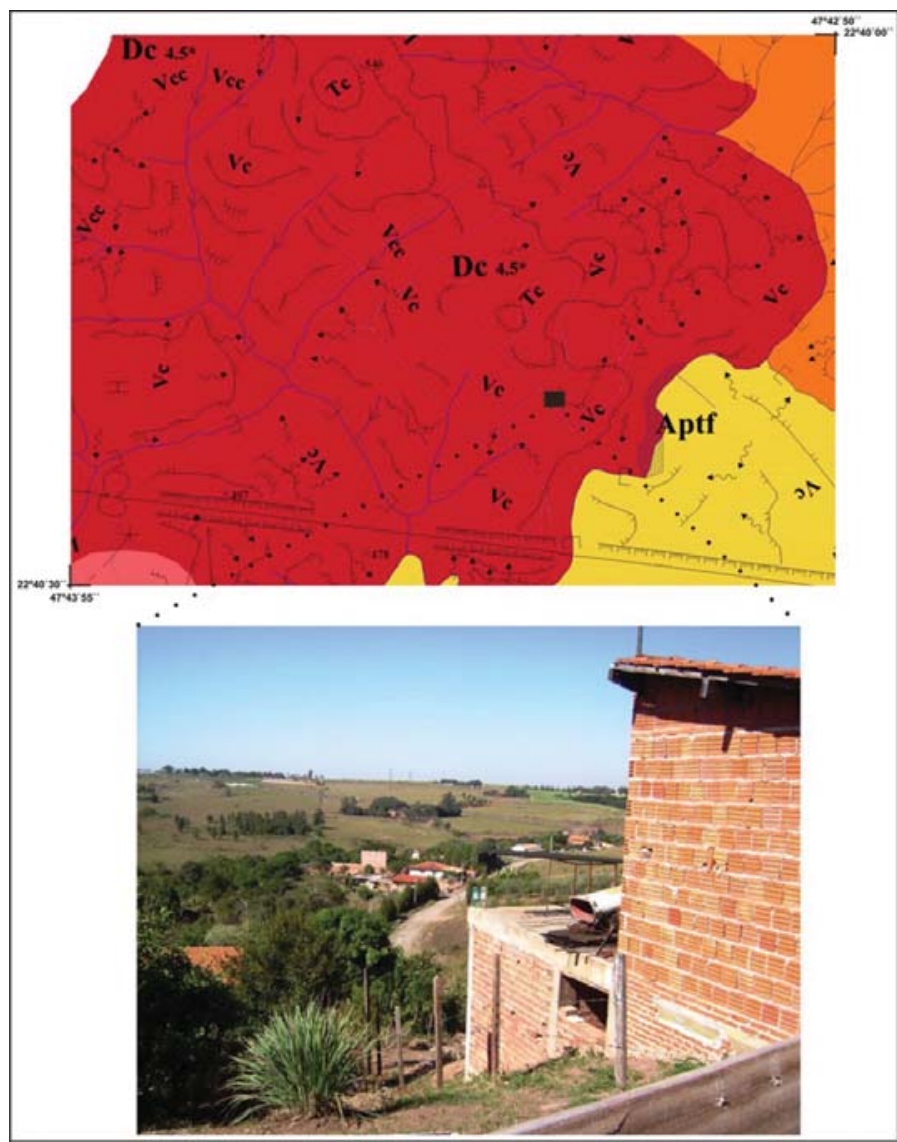

Figura 3B - Setor Dc 4.5 da Carta Geomorfológica do Setor Noroeste do Sítio Urbano de Piracicaba (SP). Ocupação em vertente declivosa e dissecada do Córrego das Ondas.

Organização: Silveira, A. (2009)

As interferências antrópicas, que dinamizam este processo denudativo, são registradas principalmente pelo cultivo de cana-de-açúcar com medidas de práticas conservacionistas, muitas vezes pouco eficazes, sobretudo em terrenos caracterizados com fragilidade do relevo "muito forte" (elevadas declividades, elevados gradientes altimétricos e elevada densidade de drenagem). Tal interferência tem contribuição singular na dinamização ou mesmo na geração de processos denudativos, seja pela exposição e remoção do material pedológico nos períodos de safra e entressafra, ou mesmo pelo corte de estradas para escoamento da produção, que se comportam como eixos do escoamento pluvial.

Além da monocultura canavieira, registram-se para o Setor a presença de fragmentos de silviculturas e de pastagens voltadas aos rebordos urbanos do bairro Santa Terezinha, como pode ser visto na foto 3. A presença destes limites já ocupados por pastagens denota tendência de ocupação deste Setor pela urbanização.

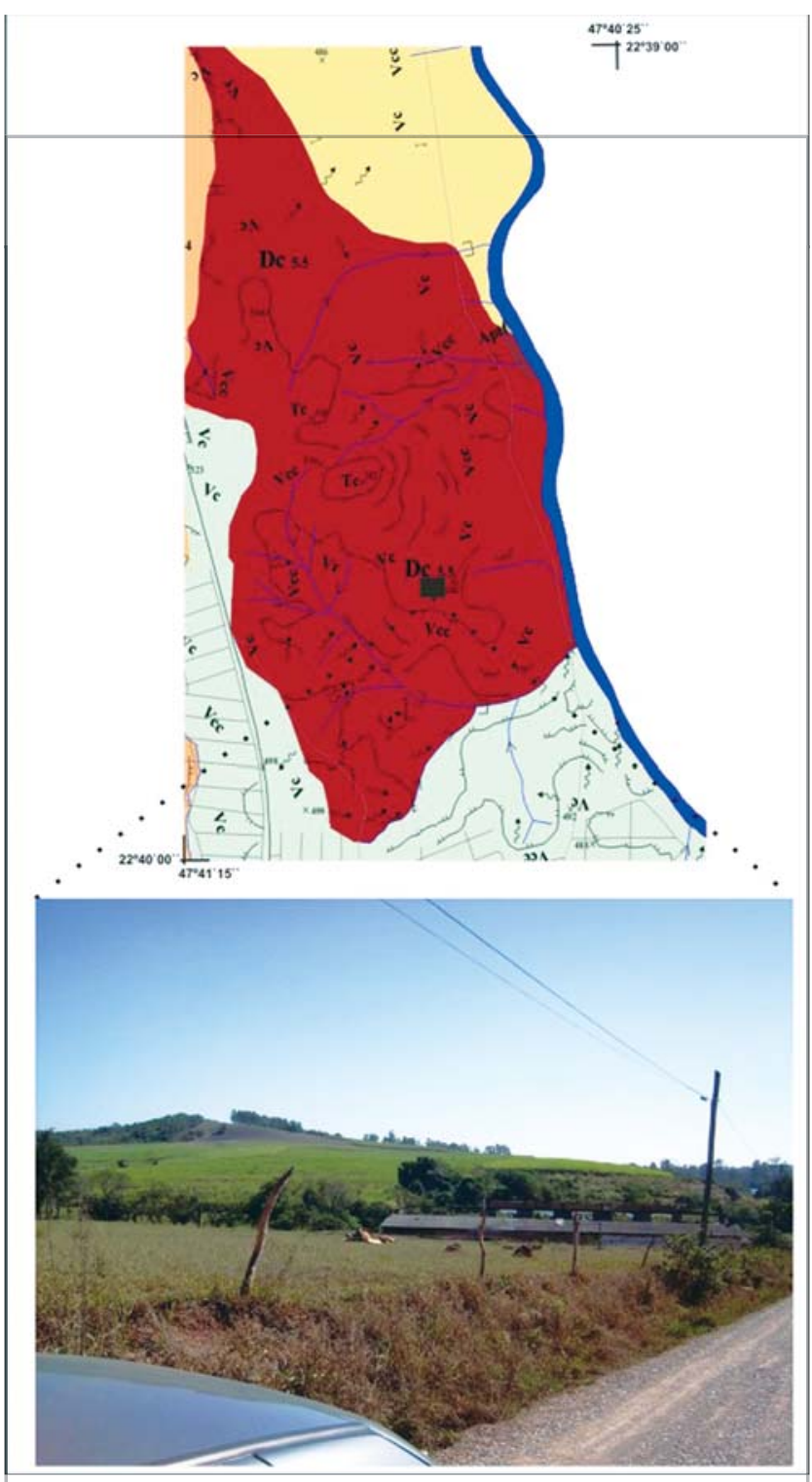

Figura 3C - Setor Dc 5.5 da Carta Geomorfológica do Setor Noroeste do Sitio Urbano de Piracicaba (SP).

Vertente dissecada de aftuente do Rio Corumbatai ocupada pela monocultura canavieira. Abaixo, presença de pastagem nas proximidades das bordas urbanas do bairro Sta. Terezinha.

Organização: Silveira, A. (2009)

\section{Considerações Finais}

A proposta metodológica adotada nesta pesquisa (ROSS, 1990, 1992 e 2001), muito utilizada para o mapeamento de grandes áreas em escalas reduzidas, também contribui de forma significativa com o planejamento territorial e ambiental, quando aplicada em áreas de pequenas extensões com escalas grandes, valorizando os táxons de detalhe $\left(3^{\circ}, 4^{\circ}, 5^{\circ}\right.$ e $6^{\circ}$ táxons).

A aplicação da proposta taxonômica do relevo no setor de expansão urbana noroeste de Piracicaba promoveu, por meio da 
elaboração e interpretação da Carta Geomorfológica, um diagnóstico detalhado das condições morfográficas, morfométricas e morfodinâmicas, sobretudo aquelas vinculadas aos processos dinamizados pela interferência antrópica, por se tratar de um ambiente de ocupação e expansão da ocupação humana via urbanização e pela presença da monocultura canavieira.

Dez unidades denudacionais de topo convexo (Dc), entre as quatorze unidades morfológicas mapeadas (Dc e Dp), foram classificadas entre as categorias de fragilidade do relevo "forte" e "muito forte", apresentando valores médios a elevados quanto às variáveis morfométricas (entalhamento dos vales, dimensão interfluvial média e declividade). Suas vertentes, predominantemente convexas, registraram muitas vezes prolongadas e escalonadas rupturas de declive, associadas a processos erosivos lineares, tanto em áreas canavieiras, quanto em bordas urbanas. As concavidades, sobretudo aquelas em cabeceiras de drenagens, normalmente entalhadas por cursos com formas de fundo de vale em "V", não deixaram de registrar os mesmos processos geomorfológicos.

Destaque foi dado a três unidades representativas. A primeira, categorizada como fragilidade do relevo "muito forte" (Dc 5.3), já densamente urbanizada, apresenta problemas geomorfológicos na periferia urbana com vertentes dissecadas nas quais se registram rupturas topográficas e sulcos erosivos. Na área intra-urbana, a canalização e desvio dos cursos fluviais, além da impermeabilização do solo, demonstram práticas de urbanização sem planejamento.

A segunda unidade morfológica ilustrada correspondeu a um Setor em processo de ocupação urbana, categorizado com fragilidade do relevo "muito forte" (Dc 4.5). Marcada pelo uso canavieiro em vertentes altamente dissecadas, com registros de formas erosivas, tais áreas vem sendo ocupadas pelo bairro Bela Vista, com a presença de chácaras e residências ocupando áreas declivosas.

A terceira unidade morfológica exemplificada, também classificada com fragilidade do relevo "muito forte" (Dc 5.5), fruto dos elevados índices morfométricos, apresenta-se marcada por escalonadas rupturas topográficas, associadas a sulcos erosivos, em áreas dominadas pela cana-de-açúcar. Tais áreas, altamente dissecadas, apresentam-se muito próximas da zona de expansão do bairro Santa Terezinha, com tendência ao processo de urbanização.

Assim, estes exemplos denotam a necessidade de medidas mais rigorosas no processo de ocupação da área estudada, tendo em vista o número significativo de unidades morfológicas com alto grau de fragilidade do relevo, com formas erosivas associadas. Denota-se também a necessidade de estudos mais rigorosos que deem suporte a orientação de áreas potencialmente favoráveis e restritas a ocupação urbana.

Dessa forma, a aplicação da proposta metodológica utilizada pôde contribuir com a caracterização geomorfológica, diagnosticando setores já ocupados pela urbanização, bem como setores em processo de ocupação e com tendência de ocupação. Junto a outras variáveis do meio físico, como documentos cartográficos de detalhe que forneçam dados sobre a geologia, pedologia, hidrologia, entre outros, o mapeamento apresentado, elaborado a partir dos níveis taxonômicos do relevo, tem contribuição relevante para o planejamento territorial.

\section{Referências Bibliográficas}

BASE AEROFOTOGRAMETRIA E PROJETOS S/A. Fotografias Aéreas. Piracicaba, 2005. Escala: 1: 25.000. BOCCO, G.; MENDOZA, M. VELÁZQUEZ, A. Remote sensing and GIS-based regional geomorphological mapping - a tool for land use planning in developing countries. Geomorphology, n. 39, p. 211-219, 2001.

GRIFFITHS, J. S.; ABRAHAM, J. K. Factors affecting the use of applied geomorphology maps to communicate with different end-user. Journal of maps, p. 201-210, 2008.

IPT, INSTITUTO DE PESQUISA TECNOLÓGICA DO ESTADO DE SÃO PAULO. Mapa Geomorfológico do Estado de São Paulo. São Paulo: IPT, 1981.

NYGAARD, N.; KOLSTRUP, E. Detailed geomorphological mapping: A potential basis for sediment flux assessment. $\mathbf{Z}$. Geomorph. N. F, Berlin, n. 52, Suppl.1, p. 199-210, jan. 2008. PENTEADO, M.M. Geomorfologia do Setor Centro-Ocidental da Depressão Periférica. São Paulo: IGEOG/USP, 1976. (Série Teses e Monografias, n.22).

PIRACICABA. Secretaria Municipal de Planejamento. Plano Diretor de Desenvolvimento de Piracicaba. Piracicaba: Prefeitura Municipal de Piracicaba, 1991.

PÓLIS, INSTITUTO DE ESTUDOS, FORMAÇÃO E ASSESSORIA EM POLÍTICAS SOCIAIS. Revisão do Plano Diretor de Desenvolvimento de Piracicaba: Relatório I - Leitura Técnica. Piracicaba: Instituto de Pesquisa e Planejamento de Piracicaba, 2003. Disponível em: $<$ http//www.ipplap.com.br/docs/ relatório_diag_PDD_1a45pdf > . Acesso em: 12 dez 2006.

ROSS, J.L.S. Geomorfologia, Ambiente e Planejamento. São Paulo: Ed. Contexto, 1990.

. O Registro Cartográfico dos Fatos Geomórficos e a Questão da Taxonomia do Relevo. Revista do Departamento de Geografia, São Paulo, n.6, p.17-30, 1992.

Geomorfologia e Geografia Aplicadas a Gestão

Territorial: Teoria e Metodologia para o Planejamento Ambiental. 2001. 322f. Tese (Livre Docência) - Faculdade de Filosofia, Letras e Ciências Humanas - FFLCH, Universidade de São Paulo-USP, São Paulo, 2001.

ROSS, J.L.S; MOROZ, I.C. Mapa Geomorfológico do Estado de São Paulo. São Paulo: FFLCH - USP/ IPT/ FAPESP, 1997. SÃO PAULO. Secretaria de Economia e Planejamento. Plano Cartográfico do Estado de São Paulo. Folha Córrego das Ondas (070/088): Carta Topográfica. Escala: 1: 10.000, 1979a.

SÃO PAULO. Secretaria de Economia e Planejamento. Plano Cartográfico do Estado de São Paulo. Folha Usina Costa Pinto (070/089): Carta Topográfica. Escala: 1: 10.000, 1979 b.

SÃO PAULO. Secretaria de Economia e Planejamento. Plano Cartográfico do Estado de São Paulo. Folha Santa Terezinha do Piracicaba (071/088): Carta Topográfica. Escala: 1: 10.000, 1979c. SÃO PAULO. Secretaria de Economia e Planejamento. Plano Cartográfico do Estado de São Paulo. Folha Piracicaba V (071/089): Carta Topográfica. Escala: 1: 10.000, 1979d.

SILVEIRA, A. Diagnóstico Ambiental do Setor Noroeste do Sítio Urbano de Piracicaba (SP): uma abordagem geográfica. 2009. Dissertação (Mestrado em Geografia - Organização do Espaço) - Instituto de Geociências e Ciências Exatas - IGCE, Universidade Estadual Paulista - UNESP, Rio Claro, 2009. 